\title{
A scatterometer record of sea ice extents and backscatter: 1992-2016
}

\author{
Maria Belmonte Rivas ${ }^{1,3}$, Ines Otosaka ${ }^{1,2}$, Ad Stoffelen ${ }^{1}$, and Anton Verhoef ${ }^{1}$ \\ ${ }^{1}$ Royal Netherlands Meteorology Institute (KNMI), de Bilt, 3731 GA, The Netherlands \\ ${ }^{2}$ Center for Polar Observation and Modelling (CPOM), University of Leeds, Leeds, LS2 9JT, UK \\ ${ }^{3}$ Instituto de Ciencias del Mar (ICM), Consejo Superior de Investigaciones Cientificas (CSIC), 08003, Barcelona, Spain
}

Correspondence: Maria Belmonte Rivas (belmonte@knmi.nl)

Received: 3 April 2018 - Discussion started: 10 April 2018

Revised: 17 July 2018 - Accepted: 21 August 2018 - Published: 14 September 2018

\begin{abstract}
This paper presents the first long-term climate data record of sea ice extents and backscatter derived from intercalibrated satellite scatterometer missions (ERS, QuikSCAT and ASCAT) extending from 1992 to the present date (Verhoef et al., 2018). This record provides a valuable independent account of the evolution of Arctic and Antarctic sea ice extents, one that is in excellent agreement with the passive microwave records during the fall and winter months but shows higher sensitivity to lower concentration and melting sea ice during the spring and summer months. The scatterometer record also provides a depiction of sea ice backscatter at $\mathrm{C}$ - and $\mathrm{Ku}$-bands, allowing the separation of seasonal and perennial sea ice in the Arctic and further differentiation between second-year (SY) and older multiyear (MY) ice classes, revealing the emergence of SY ice as the dominant perennial ice type after the historical sea ice loss in 2007 and bearing new evidence on the loss of multiyear ice in the Arctic over the last 25 years. The relative good agreement between the backscatter-based sea ice (FY, SY and older MY) classes and the ice thickness record from Cryosat suggests its applicability as a reliable proxy in the historical reconstruction of sea ice thickness in the Arctic.
\end{abstract}

\section{Introduction}

Dating as far back as 1978, passive microwave sensors provide the longest record of sea ice concentration and extents available to date and are currently established as the sea ice monitoring standard for climate studies, regardless of well-known difficulties around the detection of lower con- centration and melting sea ice conditions during the summer months (Meier et al., 2015). The scatterometer sea ice record presented here only dates back as far as 1992, but proves more sensitive to summer sea ice, its primary purpose being the conservative detection and removal of ice-contaminated scenes that compromise scatterometer wind retrievals. Previous long-term scatterometer sea ice records have been developed, spanning the decade-long QuikSCAT mission from 1999 to 2009 (Remund and Long, 2014), and extended into 2014 using the Oceansat-2 scatterometer (OSCAT) mission (Hill and Long, 2017). These precedent scatterometer records (which use maximum likelihood class discrimination based on the Ku-band pseudo-polarization $\mathrm{HH} / \mathrm{VV}$ ratio and other parameters) already underline the presence of negative biases in passive microwave sea ice extents during the melt season, but they also feature instances of missing thin ice during the growth season (Meier and Stroeve, 2008).

Some research groups have opted to blend active and passive microwave observations (i.e., the gradient and polarization ratios from radiometer, along with the $\mathrm{C}$-band anisotropy coefficient from scatterometer data) in a multisensor approach towards a sea ice edge product (Aaboe et al., 2015). The validation of the summer sea ice extents from blended records against operational sea ice charts, which also have arguable accuracy during summer, shows negative biases by up to $30 \%$ (Aaboe et al., 2016), indicating that the distinct sea ice detection skills of scatterometer data may be lost in the blend. Note though, that the primary aim of passive microwave records is the mapping of sea ice concentration, sea ice extent being only a downstream indicator. 
In this paper, an independent record of sea ice extents has been produced from intercalibrated scatterometer data: the QuikSCAT mission from 1999 to 2009 (Belmonte Rivas and Stoffelen, 2011), extended forward to the present day with the ASCAT record (Belmonte Rivas et al., 2012) and backwards to 1992 with the ERS mission (Otosaka et al., 2017) using dedicated Bayesian sea ice detection algorithms designed to maximize the skill for ocean-ice discrimination. These algorithms have been tuned to match the passive microwave sea ice extents during the fall and winter months and to remain consistent across the scatterometer overlap periods in 2000 (ERS with QuikSCAT) and 2008 (QuikSCAT with ASCAT). The stability and intercalibration of the ERS, QuikSCAT and ASCAT backscatter records is guaranteed to within $0.1 \mathrm{~dB}$ via buoy collocation (QuikSCAT; Verhoef and Stoffelen, 2016), ocean calibration (ASCAT and ERS; Verhoef and Stoffelen, 2017) and nonlinear corrections from cone metrics (ERS; Belmonte Rivas et al., 2017), offering a stable reference to verify the consistency of calibration adjustments made in passive microwave records, which - if not done properly - are known to cause discontinuities and affect long-term trends in sea ice concentration (Eisenman et al., 2014; Titchner and Rayner, 2014).

The scatterometer sea ice record also monitors the evolution of sea ice backscatter collected at C-band and Ku-band, which are widely applied to discriminate ice classes, such as first year (FY) and older (second-year, SY and multiyear, MY) sea ice in the Arctic. It is known that sea ice backscatter is modulated by surface permittivity, surface roughness and the presence of volume inhomogeneities, such as air and brine pockets or snow layers above (Ulaby et al., 1981). The main basis for FY and MY ice separation lies in older ice types becoming brighter with increased volume scattering after summer melt, although MY detection may become difficult because of patches of bright FY ice that may have locally undergone deformation. To date, the separation between Arctic FY and MY ice types using active microwaves has relied on fixed backscatter thresholds defined after visual inspection of stable winter backscatter histograms. For example, Kwok (2004) established $-14.5 \mathrm{~dB}$ as an optimal threshold for the QuikSCAT Ku-band VV polarized measurements based on visual examination of the subjective FY and MY ice boundaries in combined winter data sets of QuikSCAT and C-band SAR from RADARSAT. Other than calibration issues, the main problem with the fixed-threshold approach is the seasonal variability of the FY-MY backscatter signatures, along with sensitivity to deformed FY ice types or a developing snow cover. On the other hand, the classification of sea ice types using passive microwaves (Gloersen and Cavalieri, 1986; Comiso, 2012) has relied on the spectral gradient and polarization signatures of sea ice brightness temperatures (with MY surfaces featuring more negative spectral gradients and lower polarization than FY ice, along with lower emissivities). The spatial and temporal distributions of perennial ice derived from passive microwaves in the Arc- tic have been shown to differ somewhat from those of SAR (Kwok et al., 1996), their differences depending on atmospheric conditions and processes that affect the ice temperature and emissivity in ways that contribute to apparent concentration changes (Thomas, 1993). According to the IPCC AR5, the rate of decline in the extent of multiyear ice observed by both passive and active microwaves is consistent with the decline of old ice types estimated from the analysis of ice drift by Maslanik et al. (2007) and Tschudi et al. (2010), confirming that the Arctic has lost much of its thicker ice. Still, differences remain between scatterometer and radiometer multiyear ice extents (Comiso, 2012) associated with different sensitivities to sea ice type and snow cover, which should be better understood.

The introduction of an intercalibrated sea ice extent and backscatter record from multiple scatterometer missions (ERS, QuikSCAT, ASCAT) consistently connected from 1992 to 2016 through dedicated and validated sea ice detection and backscatter normalization algorithms is the object of this contribution. In Sect. 2, we introduce the satellite scatterometer missions and the Bayesian detection algorithms that constitute this record. In Sect. 3, the scatterometer sea ice extents are compared with passive microwave fields, showcasing their agreement and distinct sensitivities. This section also provides an overview of the long-term evolution of sea ice extents and sea ice types afforded by 25 years of scatterometer data, along with a taste of its potential to stimulate new research questions.

\section{Satellite scatterometer missions}

The continuous monitoring of the Polar regions with satellite scatterometers began in March 1992 after the launch of the European Remote Sensing (ERS) satellites, which operated a C-band instrument $(5.3 \mathrm{GHz}, \mathrm{VV}$ polarization) in global mode until January 2001. It was continued on July 1999 by the Quick Scatterometer (QuikSCAT), which operated a Kuband instrument (13.4 GHz, HH and VV polarization) up until November 2009. The scatterometer record ends with another C-band instrument that collects VV polarized backscatter at $5.3 \mathrm{GHz}$, the Advanced Scatterometer (ASCAT) on Metop-A, operating from January 2007 to the present date. The temporal spans of the satellite missions that make up the scatterometer record are illustrated in Fig. 1, showing the location of the mission overlap periods (2000 and 2008) used to verify the consistency of the sea ice extents and sea ice types across the $\mathrm{C}$ - and $\mathrm{Ku}$-band missions. For reference, the observation geometries of the constitutive ERS, QuikSCAT and ASCAT scatterometers (namely, three single-sided VV polarization fan-beams, single rotating VV and $\mathrm{HH}$ polarization pencil beams and three double-sided fan-beams) are shown in Fig. 2. While the QuikSCAT mission observes backscatter at Ku-band from an incidence angle of 54 deg (outer VV-pol beam) and 46 deg (inner HH-pol beam), the ERS and ASCAT 


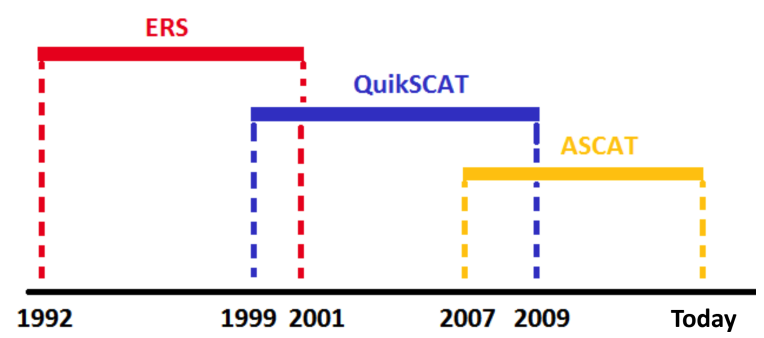

Figure 1. Temporal spans of the satellite scatterometer missions used.

missions observe backscatter at C-band from a broad range of incidence angles collected across the swath (from 18 to 64 deg in VV-pol).

\subsection{Sea ice detection with scatterometers}

The algorithm for sea ice detection with scatterometers is a maximum likelihood class discrimination approach based on probabilistic distances to ocean wind and sea ice geophysical model functions (GMFs). The GMFs describe the behavior of backscatter as a function of observation geometry (i.e., incidence and azimuth angles) and geophysical variables such as wind speed and direction or sea ice type.

\subsection{Geophysical model functions}

The ocean wind GMF, also known as the wind cone, is an empirically derived model used to derive ocean surface wind vectors operationally (see Fig. 3): we presently use CMOD7.1 (Stoffelen et al., 2017) for ERS and ASCAT, and NSCAT-4 (Verhoef and Stoffelen, 2017) for QuikSCAT. The sea ice GMF, also known as the sea ice line, is empirically derived from stable wintertime backscatter levels (Belmonte Rivas and Stoffelen, 2011; Belmonte Rivas et al., 2012; Otosaka et al., 2017). Physically, the discrimination between open water and sea ice classes is based on the separability between surface and volume scattering effects: in the QuikSCAT case, the discrimination relies on polarization and azimuthal anisotropy of backscatter (high for open water; lower for sea ice), while in the ERS ASCAT case, the discrimination relies on backscatter directivity (i.e., the derivative of backscatter with incidence angle) and azimuthal anisotropy (high for open water; lower for sea ice). Previous Bayesian formulations for sea ice detection with scatterometer data, e.g., Remund and Long (2014), have used aggregates such as mean backscatter, polarization ratio and azimuthal anisotropy as class discriminants and empirically adjusted covariances to represent the class dispersions. The advantage of the GMF approach is that the dispersion of measurements around extended class model functions is smaller than around class aggregate means, approaching the limits imposed by the scatterometer noise levels and allowing

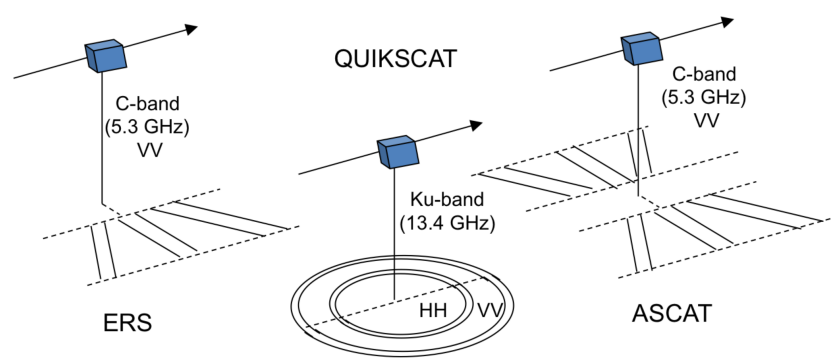

Figure 2. Observation geometries of the satellite scatterometers. (a)

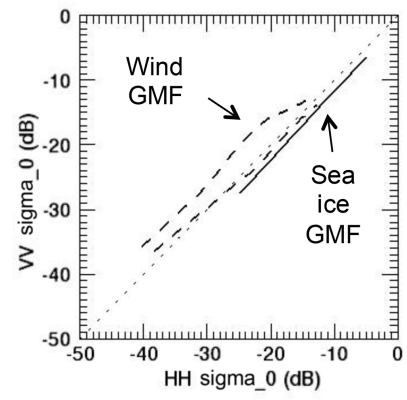

(b)

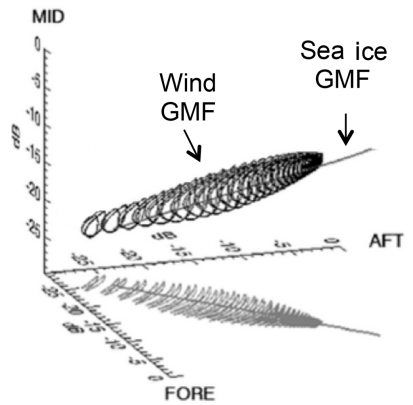

Figure 3. Ocean wind and sea ice geophysical model functions (GMFs) in the scatterometer measurement space: QuikSCAT (a) and ERS ASCAT (b). Plots adapted from Belmonte Rivas and Stoffelen (2011) and Belmonte Rivas et al. (2012).

the Bayesian method to reach its maximum discrimination power (Otosaka et al., 2017).

\subsection{Bayesian sea ice probability}

To calculate the Bayesian sea ice probability, the algorithm computes the minimum normalized squared distance (or maximum likelihood estimator, MLE) from observations $\sigma_{i}^{0}$ to the sea ice $\sigma_{\text {ice }}^{0}$ and ocean wind $\sigma_{\text {ocean }}^{0}$ model functions:

$$
\begin{array}{r}
\text { MLE }_{\text {ocean }}=\sum_{i=1, \ldots, N}\left(\sigma_{i}^{0}-\sigma_{\text {ocean }, i}^{0}\right)^{2} / \operatorname{var}\left[\sigma_{\text {ocean }, i}^{0}\right] \\
\text { MLE ice }_{\text {ice }}=\sum_{i=1, \ldots, N}\left(\sigma_{i}^{0}-\sigma_{\text {ice }, i}^{0}\right)^{2} / \operatorname{var}\left[\sigma_{\text {ice }, i}^{0}\right],
\end{array}
$$

where $N$ is the number of instrument looks $(N=4$ for QuikSCAT, $N=3$ for ERS ASCAT), and the model variances describe the tolerable (statistical average) range of departures to the GMF:

$$
\begin{gathered}
\operatorname{var}\left[\sigma_{\text {ocean }}^{0}\right]=\left(K_{\mathrm{p}}^{2}+K_{\text {geo }}^{2}\right) \sigma_{\text {ocean }}^{0}{ }^{2} \\
\operatorname{var}\left[\sigma_{\text {ice }}^{0}\right]=\left(C_{\text {mix }} K_{\mathrm{p}} \sigma_{\text {ice }}^{0}\right)^{2},
\end{gathered}
$$

where $K_{\mathrm{p}}$ represents instrumental noise, $K_{\text {geo }}$ is a measure of backscatter variability due to wind variability within the sensor footprint, and $C_{\mathrm{mix}}$ is a tolerance factor introduced in 
the sea ice model variance to allow for backscatter variability introduced by mixed open water and sea ice conditions. The conditional open water and sea ice probabilities are represented by chi-square distributions with $N-1$ and $N-2$ degrees of freedom for the sea ice and ocean wind classes:

$$
\begin{aligned}
& p\left(\operatorname{MLE}_{\text {ice }}\right)=\chi_{N-1}^{2}\left(\operatorname{MLE}_{\text {ice }}\right) \\
& p\left(\operatorname{MLE}_{\text {ocean }}\right)=\chi_{N-2}^{2}\left(\operatorname{MLE}_{\text {ocean }}\right) .
\end{aligned}
$$

The number of degrees of freedom is given by the difference between the size of the measurement space ( $N$ or the number of looks provided by the instrument) and the size of the subspace occupied by backscatter points of a given class, allowing for a two-dimensional ocean wind GMF (wind cone) and a one-dimensional sea ice GMF (sea ice line). The Bayesian sea ice posterior probability is finally calculated as follows:

$$
p(\text { ice } \mid \sigma)=\frac{p(\sigma \mid \text { ice }) p_{0}(\text { ice })}{p(\sigma \mid \text { ice }) p_{0}(\text { ice })+p(\sigma \mid \text { ocean }) p_{0}(\text { ocean })},
$$

where $p_{0}$ (ice) and $p_{0}($ ocean $)$ are a priori probabilities derived from previous observations, and $p(\sigma \mid$ ice $)$ and $p(\sigma \mid$ ocean $)$ are the conditional open water and sea ice probabilities defined in Eqs. (5)-(6). The a priori probabilities are updated at every pass using the previous pass posterior as $p_{0}$ (ice) $=$ $p($ ice $\mid \sigma)=1-p_{0}$ (ocean) and relaxed towards uncertainty once a day. In principle, we do not grant any statistical relation between sea ice probability and sea ice concentration.

Our Bayesian approach affords two parameters for algorithmic tuning: one is the tolerance factor $C_{\text {mix }}$ introduced in the sea ice model variance in Eq. (4), and the other is the probability threshold applied to the posterior in Eq. (7). With QuikSCAT, the tuning parameters were adjusted empirically to match the passive microwave extents during the fall and winter months, and verified extensively against SAR and MODIS imagery during the spring and summer months (Belmonte Rivas and Stoffelen, 2011), resulting in a $C_{\text {mix }}=3$ and a $55 \%$ probability threshold to posterior sea ice probabilities. The Bayesian parameters for the ASCAT and ERS configurations were adjusted similarly and forced to remain consistent with the QuikSCAT extents across the mission overlaps periods in 2000 and 2008, resulting in a seasonally varying $C_{\text {mix }}$ for ASCAT with a $55 \%$ probability threshold, and a seasonally varying $C_{\text {mix }}$ with a seasonally varying probability threshold ranging from $40 \%$ to $50 \%$ for ERS.

\subsection{Normalized sea ice backscatter}

In order to build a uniform record of sea ice backscatter, all the C-band measurements must be normalized to a standard incidence angle (chosen at $52.8 \mathrm{deg}$, set in the middle of the ASCAT mid-beam swath, and closest to the QuikSCAT VVpol incidence) using a model that describes the dependence of C-band sea ice backscatter on incidence angle. In the present version, the normalization assumes a linear relation between C-band backscatter and incidence angle using seaice-type-dependent coefficients (Ezraty and Cavanie, 1999). A refined incidence angle correction based on the empirical C-band sea ice backscatter model developed in Otosaka et al. (2017) is planned for a future release. The largest obstacle, though, arises from the presence of composite $\mathrm{C}$ - and $\mathrm{Ku}-$ band observations in a single-backscatter record, since their sensitivities to sea ice type differ. Both frequencies are similarly responsive to surface roughness, e.g., over deformed first-year sea ice, but Ku-band is more responsive to volume scattering in multiyear ice (Ezraty and Cavanie, 1999). As a result, the separability between deformed FY and MY ice classes is better at $\mathrm{Ku}$-band. At C-band, the disambiguation between deformed FY and MY ice classes is more difficult in terms of backscatter alone, although recourse can always be made to additional information, such as the monitoring of backscatter derivatives or the introduction of geographical constraints, such as a marginal sea mask.

\section{Historical record}

\subsection{Sea ice extents}

The time series of Arctic and Antarctic sea ice extents observed by the ERS, ASCAT and QuikSCAT scatterometers from 1992 to 2016 are shown in Fig. 4, along with the differences to the sea ice extents from the SSMI(S) passive microwave sea ice concentration (15\% threshold) algorithms from the NSIDC-0051 (Cavalieri et al., 2015) and the OSI SAF's latest major reprocessing release (OSI SAF-409a as in Tonboe et al. (2016) extended into 2016 with OSI SAF-430) in Fig. 5. The sea ice extents are constrained by a unique land mask built from the union of all active and passive sensors' land masks. No significant long-term trends are observed in the active-to-passive differences, other than a slight increase in the variability of the Arctic sea ice extent biases from 1992 to 1996, which has been attributed to data gaps in the ERS-1 mission due to SAR operations (Otosaka et al., 2017).

The correspondence between the QuikSCAT scatterometer and passive microwave sea ice extents from the NSIDC (NT-based) algorithms was extensively verified using coincident SAR imagery (Belmonte Rivas and Stoffelen, 2011) to reveal excellent agreement during the winter and fall seasons, and persistent differences during the spring and summer months. Figure 6 illustrates the seasonal pattern of active-topassive sea ice extent differences over the ERS-QuikSCAT and QuikSCAT-ASCAT overlap periods in 2000 and 2008. The agreement between the overlapping $\mathrm{C}$ - and $\mathrm{Ku}$-band scatterometer sea ice extents is very good all year round, with differences within 0.25 million $\mathrm{km}^{2}$ and an estimated ice edge accuracy of about $20 \mathrm{~km}$. The agreement between the scatterometer and passive microwave sea ice extents is of comparably high quality during the freezing season, but diminishes during the melting (spring and summer) months. 


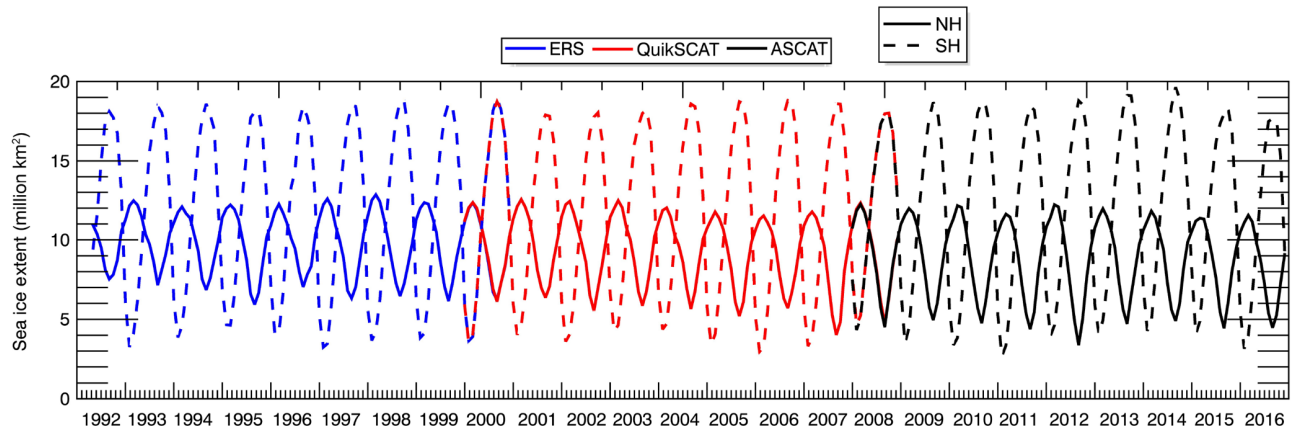

Figure 4. Time series of monthly Arctic (continuous) and Antarctic (dashed) scatterometer sea ice extents from 1992 to 2016.

(a)
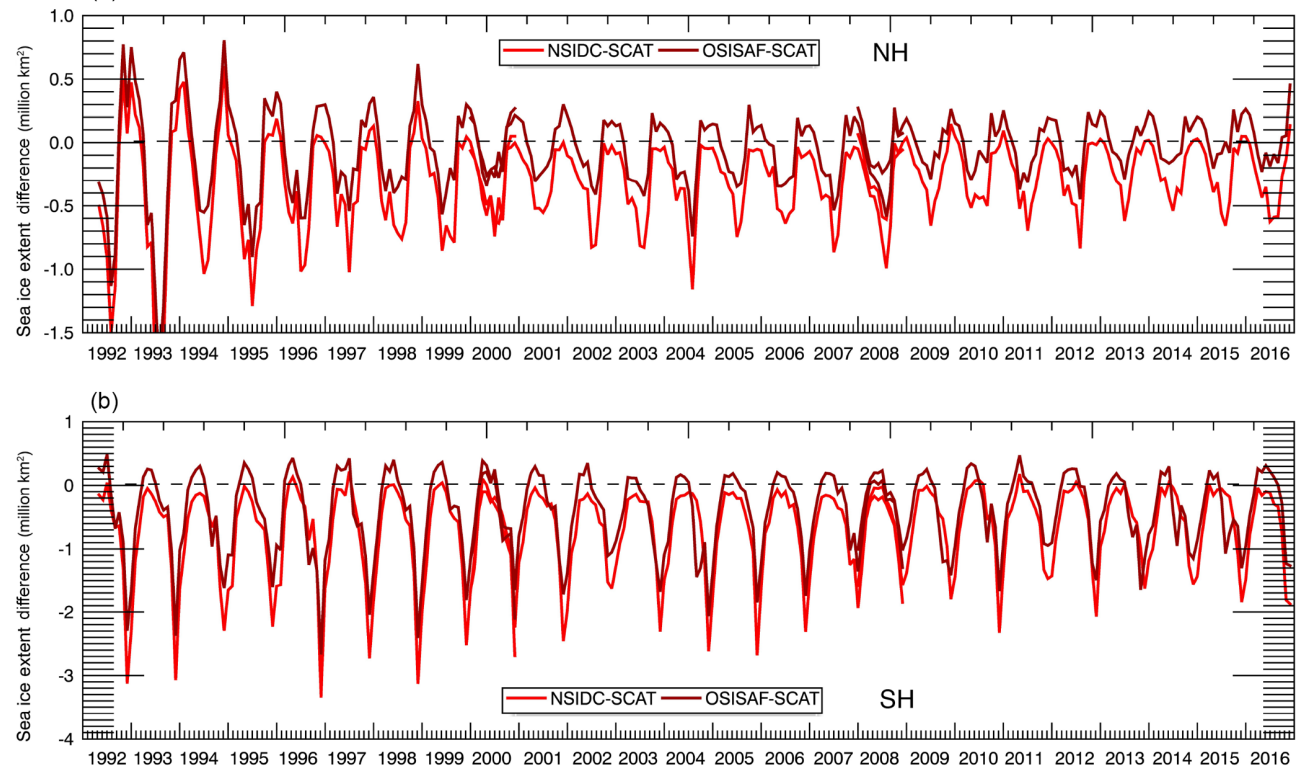

Figure 5. Time series of scatterometer sea ice extent differences to passive microwave (SSMI-based) products from NSIDC-0051 and OSI SAF-409a from 1992 to 2016 for the Arctic (a) and Antarctic (b).

Note that the amplitude of summer differences to the OSI SAF-409a product is smaller than the NSIDC-0051 product, particularly for the Arctic sea ice extents. The largest sea ice extent differences occur at the end of the summer, reaching from 0.6 to 2.0 million $\mathrm{km}^{2}$ and corresponding to estimates of the minimum sea ice extent that may differ by up to $10-30 \%$. As a result, the expression of the Arctic minimum sea ice extent in the scatterometer record may occur up to 15 days later than with passive microwaves. Figure 7 illustrates a typical spatial layout of active-to-passive sea ice extent biases for a particular late-summer day (15 September 2016). The collocated NIC chart for this particular day, which delineates the subjective extent of the summer sea ice pack (with sea ice concentrations larger than $80 \%$ and marginal sea ice excluded), showcases the higher sensitivity of the scatterometer record to lower concentration and watersaturated sea ice conditions, particularly over the confluence of the Chukchi and East Siberian seas, along with the large differences in sea ice concentration estimates from different passive microwave algorithms (of up to $30 \%$ ) in the central Arctic (Ivanova et al., 2015).

Surface wetness and melt ponding are thought to be responsible for large errors in passive microwave sea ice concentrations during spring and summer (Comiso and Kwok, 1996; Kern et al., 2016), and these errors affect the ocean heat contents and associated surface fluxes when assimilated into ocean and atmosphere reanalyses (Hirahara et al., 2016). In this context, the scatterometer record nicely complements the passive microwave products in monitoring the expanse and evolution of the lower concentration and water-saturated (rotten) late spring and summer sea ice classes. It is the different degree of inclusion of these mixed sea ice and open ocean conditions that is mainly responsible for the sea ice extent differences observed between scatterometers and passive microwaves in the spring and summer months. The reader is referred to (Belmonte Rivas and Stoffelen, 2009) for a more 

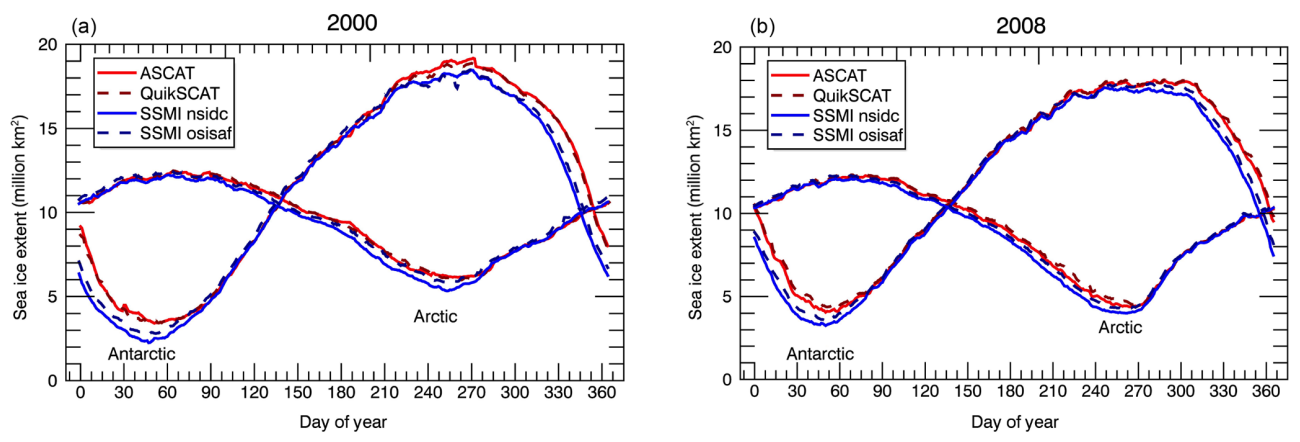

Figure 6. Comparison of ERS, QuikSCAT, ASCAT and passive microwave (OSI SAF-409a and NSIDC-0051) sea ice extents over 2000 (a) and 2008 (b).

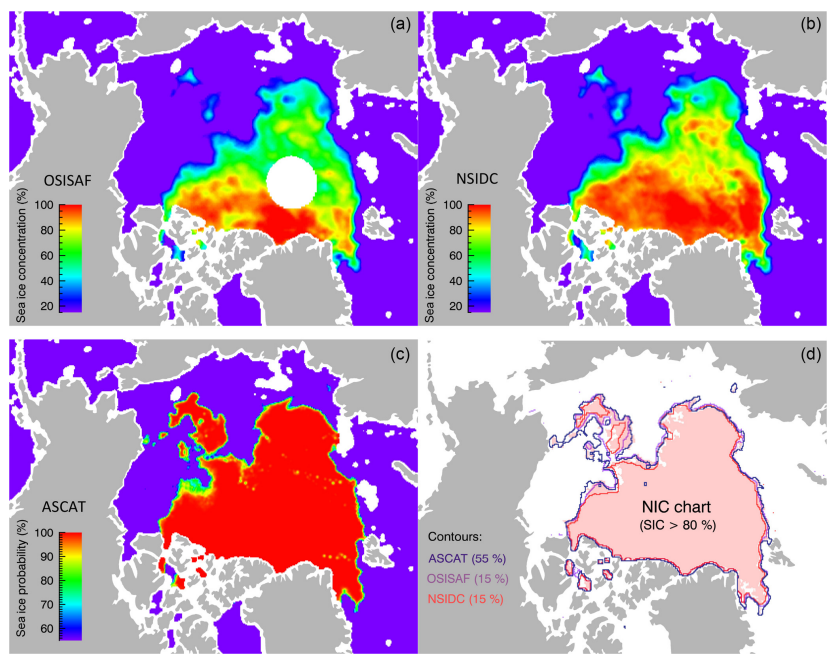

Figure 7. Comparison of summer sea ice extents on 15 September 2016 from passive microwaves (NSIDC-0051 a, OSI SAF-430 b), active microwaves (ASCAT, c) and NIC sea ice charts (d). The color scales represent sea ice concentration (a, b, lower limit $15 \%$ ), sea ice probability (c, lower limit $55 \%$ ) and NIC sea ice concentration larger than $80 \%$.

extended collection of collocated SAR and MODIS plates illustrating the nature of these differences, including a variety of scenes dominated by water-saturated (brash) ice, decaying floes, ice bands and mixtures thereof.

Figure 8 shows the long-term evolution and interannual variability of the Arctic and Antarctic minimum and maximum sea ice extents from the scatterometer and passive microwave records. These figures attest to the coincident emergence of significant events, such as the Arctic summer minima in 2007 and 2012, or the Antarctic wintertime maxima in 2014, on top of long-term trends that bear witness to Arctic sea ice decline and a modest increase in Antarctic sea ice extents. Note that, while the NSIDC algorithm ranked the summer of 2016 as second lowest in Arctic sea ice extent, tied with 2007 (NSIDC, 2016), the scatterometer record observes a somewhat slower trend in the decline of Arctic summer ice over the last 5 years and only ranks 2016 as the fifth lowest, with 4.5 (3.9) million $\mathrm{km}^{2}$ according to the scatterometer (NSIDC) record.

\subsection{Sea ice backscatter}

The monitoring of sea ice backscatter may be used to discriminate Arctic FY and MY sea ice types, but it also can be applied to estimate sea ice motion by feature tracking (Zhao et al., 2002; Lavergne et al., 2010), characterize Antarctic sea ice types (Morris et al., 1998; Haas, 2001; Willmes et al., 2011) or estimate the onset and duration of melt (Drinkwater and Liu, 2000; Howell et al., 2008). As already noted, the discrimination between Arctic FY and MY ice types using active microwaves is not without difficulty, its main hindrances being the seasonal variability of backscatter, including the effects of surface deformation, ice/snow metamorphism and a developing snow cover or the appearance of summer signatures that are more dependent on surface weather via processes such as wet snow attenuation and changes in brine temperature (Barber and Thomas, 1998). The annual cycles of MY ice coverage in the Arctic Ocean were estimated using the QuikSCAT record (1999-2009) by Kwok et al. (2009) with a fixed backscatter threshold from January to April and the record by Swan and Long (2012) with a seasonally dependent backscatter threshold from November to April. A multi-mission record was produced that extended forward in time to 2014 using Ku-band Oceansat-2 scatterometer (OSCAT) data (Lindell and Long, 2016). In order to avoid the high-backscatter FY ice in the marginal ice zone (MIZ) being classified as MY ice, Kwok et al. (2009) introduced a static geographical mask, while Lindell and Long (2016) applied a MIZ correction algorithm based on the temporal persistence of the MY signature, along with a $40 \%$ sea ice concentration mask from passive microwave data.

For the determination of the time series of Arctic MY ice coverage, we adopt the single-backscatter threshold approach. To avoid dealing with seasonal variability, we only use stable wintertime (March) backscatter maps, assuming that the backscatter signatures of the reference winter sea 

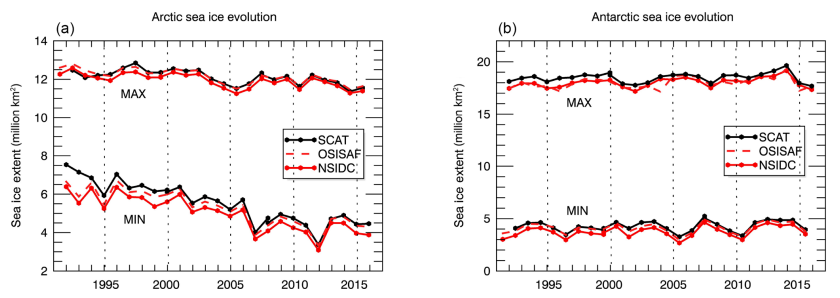

extents from scatterometers (black line) and passive microwaves (continuous and dashed red lines) from 1992 to 2016 for the Arctic (a) and Antarctic (b).

ice classes do not change with time. We also introduce a geographical mask to screen the high-backscatter response from MIZ sea ice, which has been attributed to surface deformation by compression and irreversible snow/ice metamorphism after melt-freeze events (Voss et al., 2003; Willmes et al., 2011). The geographical mask delimits the Arctic Basin (see red contours in Fig. 11) across the Fram Strait and Svalbard, to Severnaya Zemlya through Franz Josef Land (Kwok et al., 1999). An additional line from Point Barrow to Wrangel Island also excludes the Chukchi Sea from the MY area estimations. The geographical mask omits the ubiquitous presence of multiyear ice in the Greenland Sea or its episodic incursions into the marginal Chukchi, Barents and Kara seas.

For the consistency of the record, the backscatter thresholds for MY ice detection at Ku- and C-bands are matched according to their joint backscatter distributions and resulting spatial boundaries. Figure $9 \mathrm{a}$ and $\mathrm{b}$ show the joint backscatter distributions of Arctic sea ice at C-band and Ku-band for the month of March in 2000 and 2008, before application of the geographical mask. Before masking, the joint distributions of wintertime sea ice backscatter are characterized by two elongated clusters: an upper cluster corresponding to perennial (MY) ice and a lower one corresponding to seasonal (FY) ice (Ezraty and Cavanie, 1999). The cluster elongation accounts for geophysical variability, with perennial ice types getting brighter as they accumulate summer conditions and seasonal ice types becoming brighter with surface deformation and/or metamorphism. Note that the range of backscatter variability associated with deformation and/or metamorphism in the lower seasonal ice cluster $(\sim 5 \mathrm{dBs})$ is comparable at C-band and Ku-band. The signature of volume scattering, though, is stronger at Ku-band and effective at separating the rough FY and MY ice domains, which remain partly overlapping at C-band. Figure 9c, d illustrate the effectiveness of the geographical mask at removing the MIZ signature and how necessary this is for the definition of an effective separation threshold between FY and MY classes at C-band. Starting from the already established Ku-band threshold of $-14.5 \mathrm{~dB}$ for the QuikSCAT VV backscatter, which would correspond to a MY sea ice fraction of $30 \%$ according to RADARSAT

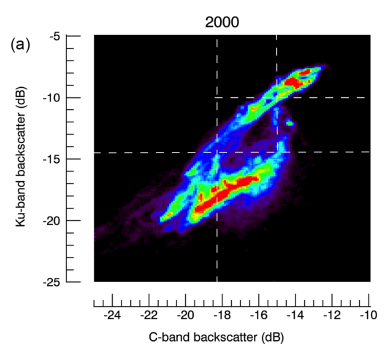

2000
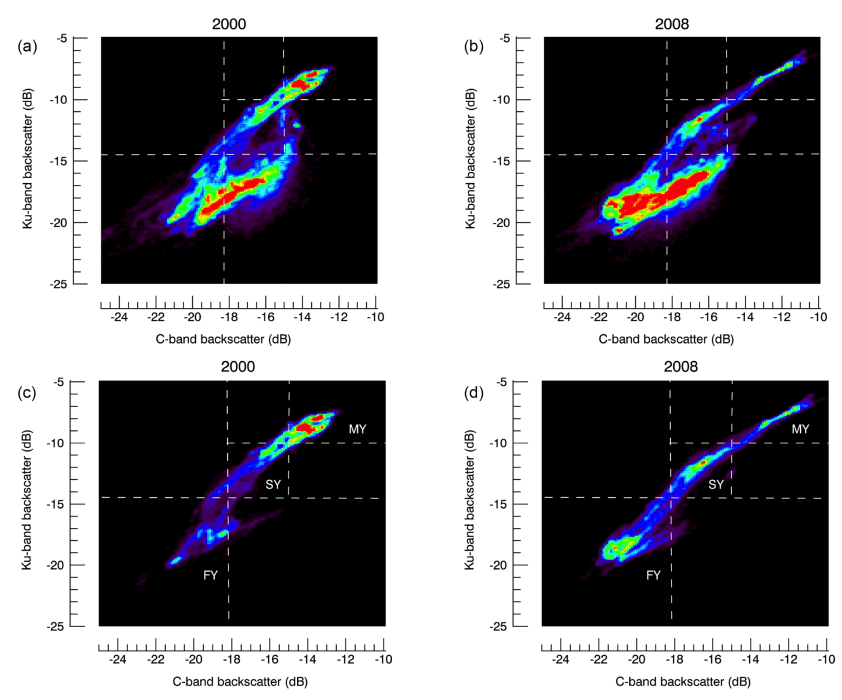

Figure 9. Joint distributions of wintertime (March) sea ice backscatter at C-band ( $x$ axis) and Ku-band ( $y$ axis) before (a, b) and after (c, d), applying the geographical mask in 2000 (a, c, ERS vs. QuikSCAT) and 2008 (b, d, ASCAT vs. QuikSCAT).

(Kwok, 2004), and aided by the correlation of the MY ice spatial boundaries at Ku- and C-bands (see Fig. 11), an optimal threshold for MY detection using C-band VV backscatter $(52.8 \mathrm{deg}$ incidence) is found at $-18.3 \mathrm{~dB}$.

Figure 10a, c show the marginal distributions of sea ice backscatter at Ku-band (a) and C-band (c) that correspond to the geographically masked joint distributions for the year 2000. The marginal backscatter distributions are characterized by two well-defined modes, associated with FY and MY sea ice types and connected by a transition range. Using spatially collocated $\mathrm{Ku}$ - and $\mathrm{C}$-band backscatter measurements, sea ice types in the transition range between the FY and MY modes may be further separated (see joint distribution in Fig. 9c) into deformed FY (in the high range of the seasonal sea ice cluster), SY ice (in the low range of the perennial sea ice cluster) and FY-MY mixtures (along the path connecting the seasonal and perennial clusters). We note that an optimal threshold for MY detection should guarantee that most of the rough FY is removed from the MY category, while collecting various fractions of SY, MY and FY-SY-MY mixtures.

After the anomalously large loss of Arctic sea ice that occurred in the summer of 2007, the shape of the wintertime sea ice backscatter histograms were remarkable altered. The earlier bimodal (FY and MY) histograms were replaced by trimodal distributions, featuring a smaller MY mode, and a new mode corresponding to SY ice emerging in the low range of the perennial sea ice cluster (Fig. 9d). The emergence of the new SY mode is also evident in the marginal distribution of Ku-band backscatter for the year 2008 (Fig. 10b), though more difficult to see in the marginal distribution of C-band data for the same year (Fig. 10d, around $-16.5 \mathrm{~dB}$ ) because of the larger influence of deformed FY in this fre- 

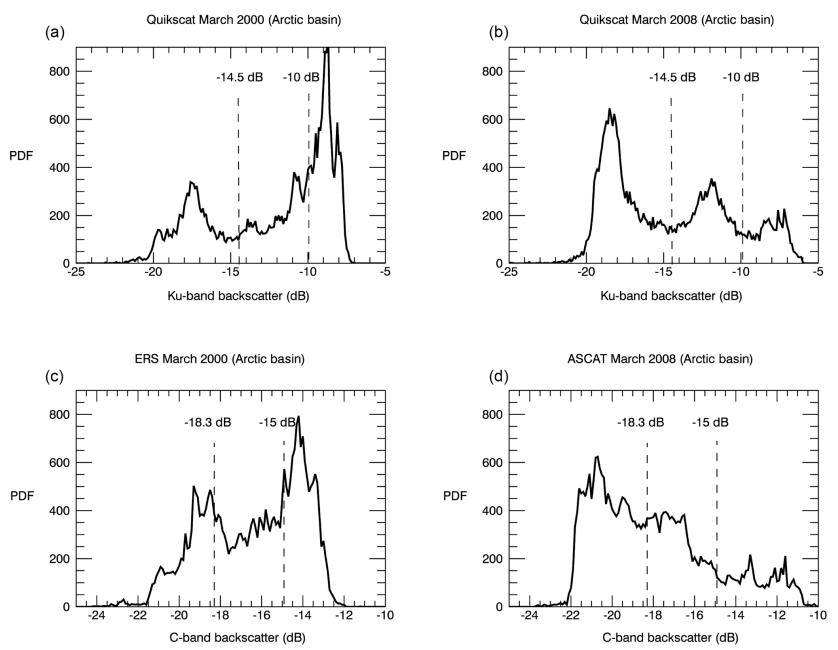

Figure 10. Marginal distributions of wintertime (March) sea ice backscatter collected at Ku-band (a, b) and C-band (c, d) after applying the geographical mask in 2000 (a, c) and 2008 (b, d).

quency and backscatter range. In order to monitor the evolution of the newly emerged SY mode, we split the perennial ice cluster into separate SY and old MY classes using an additional set of thresholds $(-10 \mathrm{~dB}$ for Ku-band and $-15 \mathrm{~dB}$ for C-band). Their location relative to the original FY and MY modes is shown in the joint and marginal distributions in Figs. 9 and 10.

The spatial distributions of the FY, SY and old MY classes that result from applying the single threshold approach on $\mathrm{Ku}-$ and C-band backscatter images are displayed in Fig. 11, along with the average sea ice age from the EASE-Grid data set NSIDC-0611 from Tschudi et al. (2016) for that period. The spatial distributions of the total MY ice class (defined as the sum of SY and old MY classes) from the scatterometer and the Lagrangian sea ice age analyses are in general good agreement, although their depictions of the SY ice class differ somewhat. We note that the old MY sea ice class has a larger geographical spread in the Lagrangian data set, particularly over areas where MY ice is exposed to strong shear stress, such as in the Beaufort Sea. From the analysis of joint backscatter distributions, we know that the scatterometer SY class is bound to contain varying amounts of FY-SYMY mixtures (and probably some deformed FY too), thus an inherent ambiguity remains regarding the dominance of pure SY ice versus mixed FY-MY combinations in a cell labeled SY, particularly before 2007. On the other hand, the Lagrangian data set is monitoring the age of the oldest ice in a cell, regardless of its weight over other ice fractions, probably biasing this product towards a larger spread of old MY ice in the Arctic. Outside of the red contour that delineates the Arctic basin mask in Fig. 11, we cannot register older ice reliably because of the strong backscatter from deformed MIZ ice.
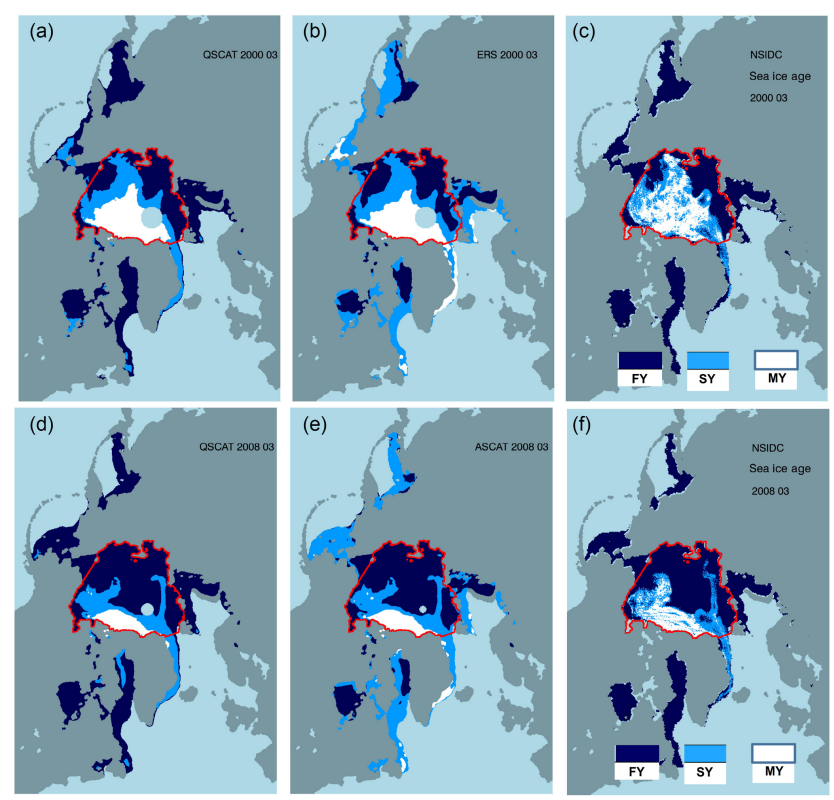

Figure 11. Geographical boundaries of wintertime FY (dark blue), SY (light blue) and MY (white) sea ice classes from Ku-band backscatter (left panel), C-band backscatter (middle panel) and NSIDC sea ice age (right panel) for 2000 (a, b, c) and 2008 (d, e, f). The contour of the geographical mask used to delimit the Arctic Basin is shown in red.

The time series of the total MY sea ice extents is shown in Fig. 12, along with the extents of the separate SY and old MY class contributions calculated using the backscatter threshold approach on wintertime (March) data collected within the geographically masked Arctic Basin. All estimates exclude a common polar gap extent of 0.354 million $\mathrm{km}^{2}$ around the North Pole. The evolution of the total MY sea ice extents derived from the scatterometer record agrees well with that derived from the NSIDC sea ice age data set, showing a MY pack that begins to lose balance around 2005, after several consecutive years of decline, and finally collapses into a large loss in 2007. The partition into total SY and old MY ice extents is also similarly depicted in both data sets, regardless of discrepancies in their spatial distributions, providing further evidence to support our claim of a newly emergent SY ice mode. Figure 12 proves that the largest decline in Arctic MY ice is borne by loss of old MY ice after 2007, with a more steady production of SY ice partly buffering those losses and driving later recovery events such as that observed in 2014.

Thus far, we have justified the definition of a separate SY ice class after the emergence of a SY mode with an entity of its own in the scatterometer backscatter histograms. The differentiation of SY and lower concentration of MY using a single frequency remains an open question. By construction, the scatterometer SY class will accommodate various fractions of deformed FY and FY-SY-MY mixtures, which we suggest may be differentiated from the homogenous SY 


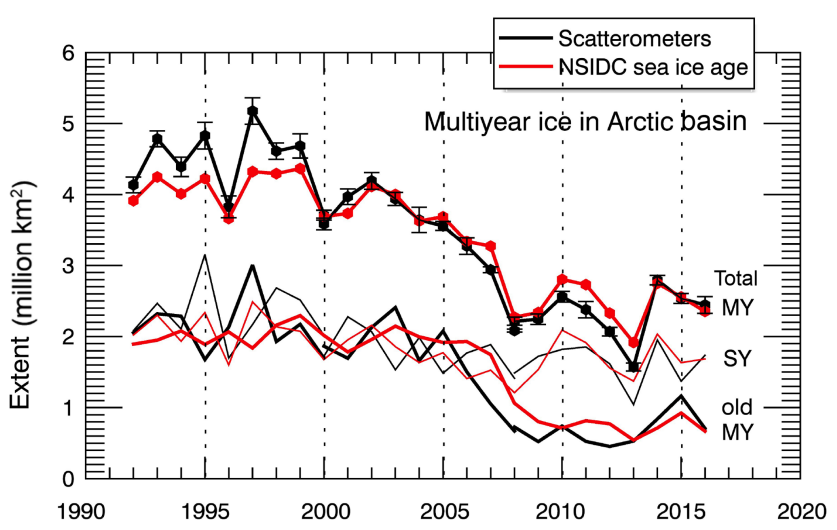

Figure 12. Time series of monthly wintertime (March) total multiyear sea ice extents (segmented into SY and older MY classes) within the Arctic Basin from the scatterometer (black) and the NSIDC sea ice age (red) records. Error bars are representative of the scatterometer class extent errors associated with a fixed backscatter threshold uncertainty of $0.1 \mathrm{~dB}$ (i.e., calibration accuracy).

ice signature by recourse to dual Ku-band and C-band observations. In this context, the reprocessed Ku-band Oceansat-2 record spanning the period from 2009 to 2014, also available in our scatterometer record, affords a new opportunity to resolve this ambiguity. We note that the scatterometer record may be helpful for checking currently developing algorithms for MY ice concentration based on satellite passive microwave or blended data, given that none of the latter products uses a separate tie point for SY ice, leaving the SY ice signature to be effectively interpreted as lower concentration MY ice. As an illustration, Fig. 13 shows the spatial distribution of MY ice according to a selection of state-ofthe-art products for the month of March 2016, including sea ice age from the scatterometer record, the NSIDC record of Tschudi et al., 2016, and the SICCI record (Korosov et al., 2018), MY ice concentration from the OSI SAF-403 (Aaboe et al., 2016), the University of Bremen algorithm (Ye et al., 2016) and the SICCI algorithm (Korosov et al., 2018) and sea ice thickness from the AWI Cryosat-2 data set (Ricker et al., 2014). The monthly averaged MY ice concentration is calculated directly over the daily MY ice concentrations from the SICCI and Bremen products. Note that the OSI SAF-403 is not a sea ice concentration product but a FY or MY classification. In this case, a daily MY concentration is defined ( $100 \%$ for the MY class, $50 \%$ for the ambiguous class and $0 \%$ for the FY and OW classes) and a monthly average MY concentration is calculated as above. The monthly averaged sea ice age is calculated over the weekly NSIDC grids (using weeks 9 to 12) and over the daily SICCI grids, and the SY ice class is defined for a monthly average sea ice age between 1.5 and 2.5 years.

Even though the general representation of MY ice is similar across all products, there are remarkable differences as well, mainly regarding the distribution of the old MY ice class north of the Canadian Arctic Archipelago (CAA, with large variations across the sea ice age records) and the presence of MY ice north of the Beaufort and Chukchi seas (with notable differences between the MY ice concentration records). The ice thickness product is revealing in that the thickest sea ice (more than $3 \mathrm{~m}$ thick and most likely associated with old MY ice) appears mostly confined to a thin strip along the CAA shore (see label A in Fig. 13g, in agreement with the scatterometer old MY ice class) and shows no traces of thick ice north of the Beaufort and Chukchi seas (see label B in Fig. 13g, in disagreement with some of the MY concentrations and the NSIDC sea ice age record). Further, we note a large extension of very thick ice north of Greenland (more than $3 \mathrm{~m}$ thick; see label C in Fig. 13g), which is labeled as SY ice in the scatterometer record (probably ridged SY ice converging into Fram Strait), which effectively appears as low concentration MY ice in the University of Bremen and SICCI algorithms, suggesting problems with the tie point definition in MY ice concentration algorithms (not in the OSI SAF-403 data set, because it is reports MY presence, not concentration). Finally, we find relative good agreement between the scatterometer SY ice class and the $2.0 \mathrm{~m}$ isoline from the ice thickness record, suggesting the utilization of the backscatter record as a reliable proxy for the estimation of thick sea ice thickness in the Arctic, in much the same way as Tschudi et al. (2016a) propose relating the NSIDC sea ice age to ice thickness. Another interesting feature refers to the thin tongue of older ice extending across the Arctic Basin towards the New Siberian Islands (see label D in Fig. 13g), which is seen by all products, even faintly in the AWI sea ice thickness, but falls below the SY threshold in the scatterometer-based MY ice classification. We cannot offer an explanation for this feature at the moment, other than acknowledging that efforts towards ensuring the consistency among MY ice products in the Arctic should warrant further research.

Noting the lack of extensive in situ validation sources for satellite-based data sets, one should rely on consistency among products as the best approach for checking retrievals. Yet, the differences just noted in this section make it clear that further effort towards the optimal integration of active and passive microwaves is necessary, not only for the classification of sea ice types, but for the determination of summer sea ice edge and concentrations.

\section{Conclusions}

We present the first intercalibrated long-term record of sea ice extents and backscatter derived from satellite scatterometer missions (ERS, QuikSCAT and ASCAT) extending from 1992 to the present date. The scatterometer record, the continuation of which is guaranteed by the Metop ASCAT (B and C) and EPS-SG series into the future, provides a valuable independent account of the state of Arctic and Antarctic 
(a)

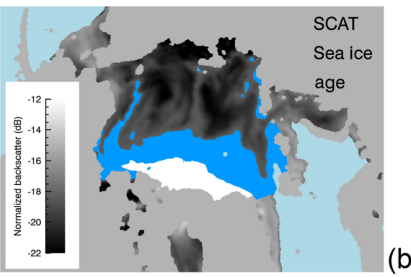

(d)

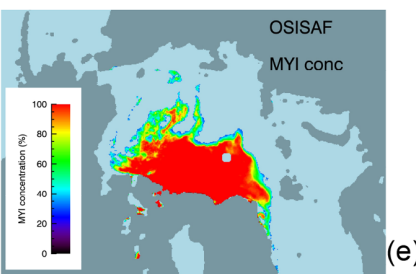

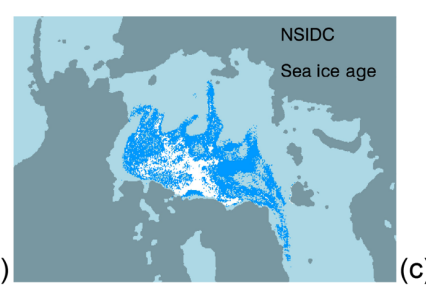
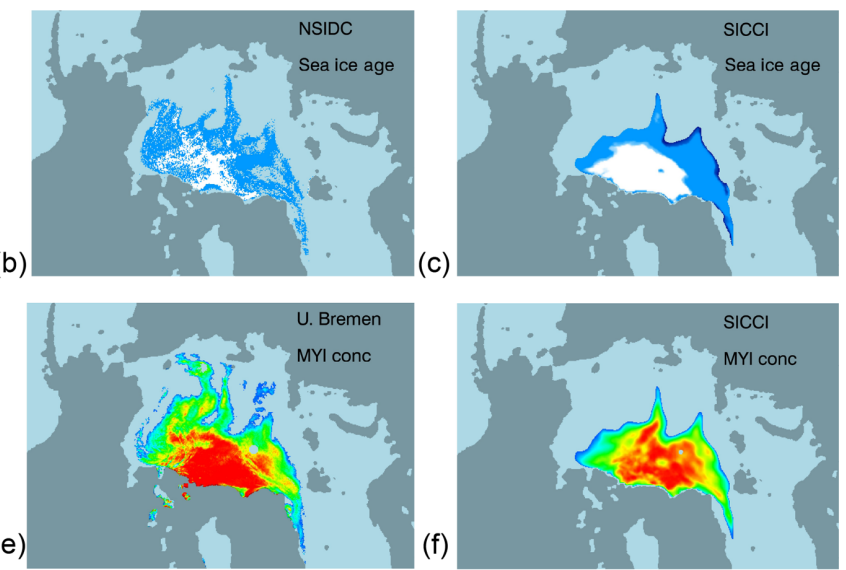

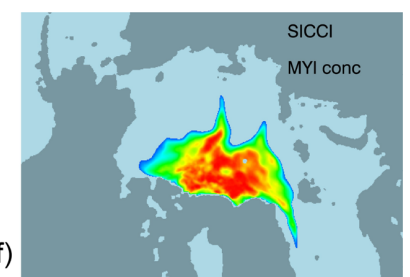

(g)

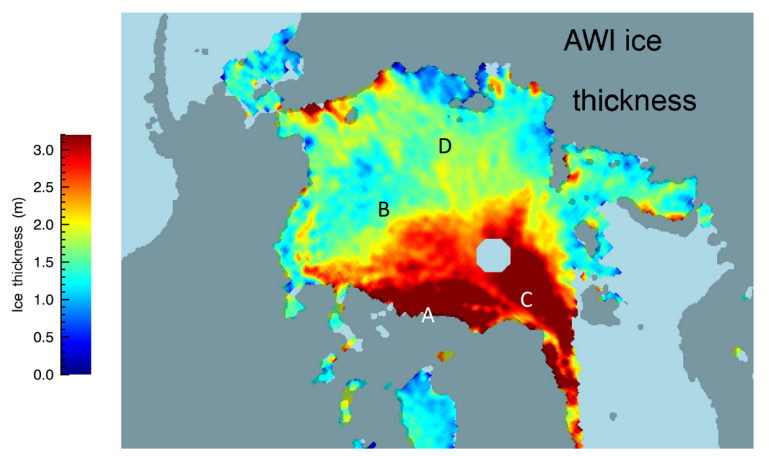

Figure 13. Different observation-based products for the representation of multiyear ice in March 2016. (a-c) Sea ice age (light blue is SY ice, white is old MY ice): (a) is from the scatterometer record, (b) is the NSIDC sea ice age and (c) is from the SICCI algorithm. (d-f) Multiyear ice concentration (MY > 30\%): (d) from the OSI SAF-403, (e) the University of Bremen algorithm and (f) the SICCI algorithm. (g) Sea ice thickness. See text for labels.

sea ice cover, with daily sea ice extent and backscatter maps available at www.knmi.nl/scatterometer/ice_extents (last access: 4 September 2018).

The scatterometer sea ice extents show excellent agreement with passive microwave fields in the fall and winter seasons, with differences within 0.25 million $\mathrm{km}^{2}$ and an estimated ice edge accuracy of about $20 \mathrm{~km}$, but show enhanced sensitivity to lower concentration and water-saturated sea ice conditions during the spring and summer months, as verified by numerous comparisons to MODIS and SAR imagery. The sea ice concentrations derived from satellite passive microwave brightness temperatures are affected by surface wetness during the melt season, typically underestimating the summer sea ice concentration and summer sea ice extent by up to $30 \%$ and having a nonnegligible impact on the ocean heat contents and surface fluxes when assimilated into reanalyses. In this context, the scatterometer sea ice extents and probabilities nicely complement the passive microwave products in providing a basis to monitor the occurrence of sea ice concentration errors due to surface wetness and to delineate the expanse and evolution of the rotten late spring and summer ice classes.
The scatterometer backscatter maps also provide enhanced means to differentiate between sea ice types. Our study of the evolution of the wintertime seasonal (FY) and perennial (MY) ice classes in the Arctic Basin from 1992 to the present day shows, in good agreement with the NSIDC sea ice age data set, a MY ice pack that begins to lose balance around 2005, after several consecutive years of decline, and finally collapses into a record loss in 2007. The scatterometer maps also reveal the emergence of a new mode in the backscatter histograms after the record sea ice loss in 2007, bearing striking resemblance in both temporal evolution and spatial distribution with the SY ice class of the NSIDC sea ice age data set. Monitoring the evolution of the complementary SY and old MY ice classes shows that the decline in the total MY ice extent observed in the Arctic was driven by the loss of older MY ice, while a more steady production of SY ice acted to stabilize the losses and contributed to later recovery events such as that observed in 2014.

We note that the differentiation between SY, deformed FY and lower concentration (but older) MY ice may be difficult using single-frequency backscatter. The simultaneous combination of C-band and Ku-band backscatter measurements allows further differentiation of sea ice types into deformed 
FY (high C-band, low Ku band), SY ice (low C-band, high $\mathrm{Ku}$-band) and FY-MY mixtures (moderate $\mathrm{Ku}$ - and $\mathrm{C}$-band responses), suggesting new approaches to their disambiguation. As such, the combination of coincident Ku-band and C-band missions (such as during the QuikSCAT overlap in 2000 and 2008 or the Oceansat-2 overlap from 2009 to 2014), along with the use of contemporaneous multi-frequency passive microwave data, affords renewed potential towards the generation of combined time series of areal estimates of different ice classes, as demonstrated in Remund et al. (2000), which can be used to guide reanalyses.

The scatterometer backscatter record is helpful for checking currently developing algorithms for MY ice concentration based on satellite passive microwave or blended data, given that none of the latter products use a separate tie point for SY ice, leaving the SY ice signature to be effectively interpreted as lower concentration MY ice. The comparison of a selection of state-of-the-art data sets for the representation of MY ice (including sea ice age, MY ice concentration and ice thickness estimates) in the Arctic reveals some notable inconsistencies, mainly regarding the ambiguity between compact SY and lower MY ice fractions, the spatial distribution of old MY ice in the sea ice age records and the apparently spurious presence of MY ice in the central Arctic in some of the MY concentration records derived from satellite passive microwaves. The relative good agreement between the backscatter-based sea ice (FY, SY and older MY) classes and the ice thickness record from Cryosat suggests its applicability as a reliable proxy in the historical reconstruction of sea ice thickness in the Arctic.

Noting the lack of extensive in situ validation sources for satellite-based data sets, one should rely on consistency among products as the best approach for checking retrievals. Yet, the differences among state-of-the-art products noted in this paper make it clear that further effort towards the optimal integration of active and passive microwaves is necessary, not only for the classification of sea ice types, but for the determination of summer sea ice edge and concentrations.

Data availability. The scatterometer record of sea ice extents and backscatter used to conduct this research is available at http://www. knmi.nl/scatterometer/ice_extents (last access: 4 September 2018) and listed as supplementary data sets in this manuscript.

Author contributions. MBR and AS developed the methodology for sea ice detection using scatterometer data. MBR, IO and AV processed the scatterometer sea ice record. MBR, IO and AS interpreted the results. MBR wrote the manuscript.

Competing interests. The authors declare that they have no conflict of interest.
Acknowledgements. The authors would like to acknowledge the financial support of the ESA Scirocco project, the EUMETSAT OSI SAF for the provision of backscatter data, our KNMI colleague Jeroen Verspeek for his insights, and the NASA and NSIDC public data archives as essential towards the completion of this activity. Processing of the AWI CryoSat-2 (PARAMETER) ice thickness is funded by the German Ministry of Economics Affairs and Energy (grant 50EE1008) and data obtained from http://www.meereisportal.de (grant REKLIM-2013-04).

Edited by: Christian Haas

Reviewed by: two anonymous referees

\section{References}

Aaboe, S., Breivik, L. A., and Eastwood, S.: ATBD for the OSI SAF Global Sea Ice Edge and Type Product, OSI SAF report CDOP2/MET-Norway/SCI/MA/208, http://osisaf.met.no/ docs/osisaf_cdop2_ss2_atbd_sea-ice-edge_type_v1p2.pdf (last access: 4 September 2018), 2015.

Aaboe, S., Breivik, L. A., Eastwood, S., and Sorensen, A.: Global Sea Ice Edge and Type Validation Report, OSI SAF report CDOP2/MET-Norway/SCI/RP/224, http://osisaf.met.no/docs/ osisaf_cdop2_ss2_valrep_sea-ice-edge-type_v2p1.pdf (last access: 4 September 2018), 2016.

Barber, D. G. and Thomas, A.: The influence of cloud cover on the radiation budget, physical properties and microwave scatterin coefficients of first-year and multi-year ice, IEEE T. Geosci. Remote Sens., 36, 38-50, 1998.

Belmonte Rivas, M. and Stoffelen, A.: "Near Real-Time sea ice discrimination using SeaWinds on QuikSCAT", OSI SAF Visiting Scientist Report, SAF/OSI/CDOP/KNMI/TEC/TN/168, available at: https://cdn.knmi.nl/system/data_center_publications/ files/000/068/084/original/sea_ice_osi_saf_final_report.pdf? 1495621021 (last access: 4 September 2018), 2009.

Belmonte Rivas, M. and Stoffelen, A.: New Bayesian algorithm for sea ice detection with QuikSCAT, IEEE T. Geosci. Remote Sens., 49, 1894-1901, 2011.

Belmonte Rivas, M., Verspeek, J., Verhoef, A., and Stoffelen, A.: Bayesian sea ice detection with the Advanced Scatterometer ASCAT, IEEE T. Geosci. Remote Sens., 50, 2649-2657, 2012.

Belmonte Rivas, M., Stoffelen, A., Verspeek, J., Verhoef, A., Neyt, X., and Anderson, C.: Cone metrics: a new tool for the intercomparison of scatterometer records, IEEE J. Sel. Top. Appl. Earth Observ. Remote Sens., 10, 2195-2204, 2017.

Cavalieri, D. J., Parkinson, C. L., Gloersen, P., and Zwally, H.: Sea ice concentrations from NIMBUS-7 SMMR and DMSP SSM/ISSMIS passive microwave data (version 1), Boulder, CO, USA, NASA National Snow and Ice Data Center Distributed Active Archive Center. Digital media, 2015 (Note: from 1992 through 2015, the reprocessed data labelled NSIDC-0051 are used; to complete the series in 2016, the NRT data labelled NSIDC-0081 are used), 2015.

Comiso, J. C.: Large decadal decline of the Arctic multiyear ice cover, J. Climate, 25, 1176-1193, https://doi.org/10.1175/JCLID-11-00113.1, 2012. 
Comiso, J. C. and Kwok, R.: Surface and radiative characteristics of the summer Arctic sea ice cover from multisensor satellite observations, J. Geophys. Res., 101, 28397-28416, 1996.

Drinkwater, M. R. and Liu, X.: Seasonal to Interannual variability in Antarctic sea ice surface melt, IEEE T. Geosci. Remote Sens., 38, 1827-1842, 2000.

Eisenman, I., Meier, W. N., and Norris, J. R.: A spurious jump in the satellite record: has Antarctic sea ice expansion been overestimated?, The Cryosphere, 8, 1289-1296, https://doi.org/10.5194/tc-8-1289-2014, 2014.

Ezraty, R. and Cavanie, A.: Intercomparison of backscatter maps over arctic sea ice from NSCAT and the ERS scatterometer, J. Geophys. Res., 104, 11471-11483, 1999.

Haas, C.: The seasonal cycle of ERS scatterometer signatures over perennial Antarctic sea ice and associated surface ice properties and processes, Ann. Glaciol., 33, 69-73, 2001.

Hill, J. C. and Long, D. G.: Extension of the QuikSCAT sea ice extent data set with OSCAT data, IEEE Geosci. Remote Sens. Lett., 14, 92-96, 2017.

Hirahara, S., Alonso Balmaseda, M., Boisseson, E., and Hersbach, H.: Sea surface temperature and sea ice concentration for ERA5, ERA report series, 26, ECMWF, 2016.

Howell, S., Tivy, A., Yackel, J. J., Else, B., and Duguay, C. R.: Changing sea ice melt parameters in the Canadian Arctic Archipelago: Implications for the future presence of multiyear ice, J. Geophys. Res., 113, C09030, https://doi.org/10.1029/2008JC004730, 2008.

Ivanova, N., Pedersen, L. T., Tonboe, R. T., Kern, S., Heygster, G., Lavergne, T., Sørensen, A., Saldo, R., Dybkjær, G., Brucker, L., and Shokr, M.: Inter-comparison and evaluation of sea ice algorithms: towards further identification of challenges and optimal approach using passive microwave observations, The Cryosphere, 9, 1797-1817, https://doi.org/10.5194/tc9-1797-2015, 2015.

Kern, S., Rösel, A., Pedersen, L. T., Ivanova, N., Saldo, R., and Tonboe, R. T.: The impact of melt ponds on summertime microwave brightness temperatures and sea-ice concentrations, The Cryosphere, 10, 2217-2239, https://doi.org/10.5194/tc-10-22172016, 2016.

Korosov, A. A., Rampal, P., Pedersen, L. T., Saldo, R., Ye, Y., Heygster, G., Lavergne, T., Aaboe, S., and Girard-Ardhuin, F.: A new tracking algorithm for sea ice age distribution estimation, The Cryosphere, 12, 2073-2085, https://doi.org/10.5194/tc-12-20732018, 2018.

Kwok, R.: Annual cycles of multiyear sea ice coverage of the Arctic Ocean: 1999-2003, J. Geophys. Res., 109, C11004, https://doi.org/10.1029/2003JC002238, 2004.

Kwok, R., Comiso, J. C., and Cunningham, G. F.: Seasonal characteristics of the perennial ice cover of the Beaufort Sea, J. Geophys. Res., 101, 28417-28439, 1996.

Kwok, R., Cunningham, G. F., and Yueh, S.: Area balance of the Arctic Ocean perennial ice zone: October 1996 to April 1997, J. Geophys. Res., 104, 25747-25759, 1999.

Kwok, R., Cunningham, G. F., Wensnahan, M., Rigor, I., Zwally, H. J., and Yi, D.: Thinning and volume loss of the Arctic Ocean sea ice cover: 2003-2008, J. Geophys. Res., 114, C07005, https://doi.org/10.1029/2009JC005312, 2009.

Lavergne, T., Eastwood, S., Tehhah, Z., Schyberg, H., and Breivik, L. A.: Sea ice motion from low-resolution satellite sensors: an alternative method and its validation in the Arctic, J. Geophys. Res., 115, C10032, https://doi.org/10.1029/2009JC005958, 2010.

Lindell, D. B. and Long, D. G.: Multiyear Arctic sea ice classification using OSCAT and QuikSCAT, IEEE T. Geosci. Remote Sens., 54, 167-175, 2016.

Maslanik, J. A., Fowler, C., Stroeve, J., Drobot, S., Zwally, J., Yi, D., and Emery, W.: A younger, thinner Arctic ice cover: Increased potential for rapid, extensive sea-ice loss, Geophys. Res. Lett., 34, L24501, https://doi.org/10.1029/2007GL032043, 2007.

Meier, W. N. and Stroeve, J.: Comparison of sea-ice extent and ice edge location estimates from passive microwave and enhanced resolution scatterometer data, Ann. Glaciol., 40, 65-70, 2008.

Meier, W. N., Fetterer, F., Stewart, J. S., and Helfrich, S.: How do sea-ice concentrations from operational data compare with passive microwave estimates? Implications for improved model evaluations and forecasting, Ann. Glaciol., 56, 332-340, https://doi.org/10.3189/2015AoG69A694, 2015.

Morris, K., Jeffries, M. O., and Li, S.: Sea ice characteristics and seasonal variability of ERS-1 SAR backscatter in the Bellingshausen Sea, Antarctic Sea Ice: Physical Processes, Interactions and Variability, Antarc. Res. Ser., 74, 213-242, 1998.

NSIDC: 2016 ties with 2007 for second lowest Arctic sea ice minimum, available at: http://nsidc.org/arcticseaicenews/2016/09/ 2016-ties-with-2007-for-second-lowest-arctic-sea-ice-minimum, last access: 15 September 2016

Otosaka, I., Belmonte Rivas, M., and Stoffelen, A.: Bayesian sea ice detection with the ERS Scatterometer ESCAT, IEEE T. Geosci. Remote Sens., 56, 2248-2254, https://doi.org/10.1109/TGRS.2017.2777670, 2017.

Remund, Q. P. and Long, D. G.: A decade of QuikSCAT scatterometer sea ice extent data, IEEE T. Geosci. Remote Sens., 52, 42814290, 2014.

Remund, Q. P., Long, D. G., and Drinkwater, M. R.: An iterative approach to multisensory sea ice classification, IEEE T. Geosci. Remote Sens., 38, 1843-1856, 2000.

Ricker, R., Hendricks, S., Helm, V., Skourup, H., and Davidson, M.: Sensitivity of CryoSat-2 Arctic sea-ice freeboard and thickness on radar-waveform interpretation, The Cryosphere, 8, 16071622, https://doi.org/10.5194/tc-8-1607-2014, 2014.

Stoffelen, A., Verspeek, J., Vogelzang, J., and Verhoef, A.: The CMOD7 Geophysical Model Function for ASCAT and ERS wind retrievals, IEEE J. Sel. Top. Appl. Earth Observ. Remote Sens., 10, 2123-2134, 2017.

Swan, A. M. and Long, D. G.: Multiyear Arctic sea ice classification using QuikSCAT, IEEE T. Geosci. Remote Sens., 50, 3317 3326, 2012.

Thomas, D. R.: Arctic sea ice signatures for passive microwave algorithms, J. Geophys. Res., 98, 10037-10052, https://doi.org/10.1029/93JC00140, 1993.

Titchner, H. A. and Rayner, N. A.: The Met Office Hadley Center sea ice and sea surface temperature data set, version $2: 1$. Sea ice concentrations, J. Geophys. Res.-Atmos., 119, 2864-2889, https://doi.org/10.1002/2013JD020316, 2014.

Tonboe, R. T., Eastwood, S., Lavergne, T., Sørensen, A. M., Rathmann, N., Dybkjær, G., Pedersen, L. T., Høyer, J. L., and Kern, S.: The EUMETSAT sea ice concentration climate data record, The Cryosphere, 10, 2275-2290, https://doi.org/10.5194/tc-102275-2016, 2016. 
Tschudi, M. A., Fowler, C, Maslanik, J. A., and Stroeve, J.: Tracking the movement and changing surface characteristics of Arctic sea ice, IEEE J. Select. Top. Earth Obs. Remote Sens., 10, 536540, https://doi.org/10.1109/JSTARS.2010.2048305, 2010.

Tschudi, M. A., Stroeve, J., and Stewart, J. S.: Relating the age of Arctic sea ice to its thickness, as measured during NASA's ICEsat and IceBridge, Remote Sens., 8, 457, https://doi.org/10.3390/rs8060457, 2016.

Tschudi, M., Fowler, C., Maslanik, J., Stewart, J. S., and Meier, W.: EASE-Grid Sea Ice Age (V3), Boulder, Colorado USA: NASA National Snow and Ice Data Center Distributed Active Archive Center, 2016.

Ulaby, F. T., Moore, R. K., and Fung, A. K.: Microwave Remote Sensing: Active and Passive, Volume III: From Theory To Applications, Artech House Publishers, London, UK, 1981.

Verhoef, A. and Stoffelen, A.: Reprocessed SeaWinds L2 winds Product User Manual (PUM), Version 1.4, SAF/OSI/CDOP2/KNMI/TEC/MA/220, EUMETSAT, February 2016.

Verhoef, A. and Stoffelen, A.: Algorithm Theoretical Basis Document (ATBD) for the OSI SAF wind products, Version 1.4, SAF/OSI/CDOP2/KNMI/SCI/MA/197, EUMETSAT, February 2017.
Verhoef, A., Belmonte Rivas, M., and Stoffelen, A.: ASCAT-A Arctic daily sea ice extent and backscatter maps (Version 1.0) [Data set], Royal Netherlands Meteorological Institute (KNMI), https://doi.org/10.21944/ascat_a_nh_sea_ice_v1.0, 2018.

Voss, S., Heygster, G., and Ezraty, R.: Improving sea ice type discrimination by the simultaneous use of SSM/I and scatterometer data, Polar Res., 22, 35-42, 2003.

Willmes, S., Haas, C., and Nicolaus, M.: High radar backscatter regions on Antarctic sea ice and their relation to sea ice and snow properties and meteorological conditions, Int. J. Remote Sens., 32, 3967-3984, 2011.

Ye, Y., Shokr, M., Heygster, G., and Spreen, G.: Improving multiyear ice concentration estimates with ice drift, Remote Sens., 8, 397, https://doi.org/10.3390/rs8050397, 2016.

Zhao, Y., Liu, A. K., and Long, D. G.: Validation of sea ice motion from QuikSCAT with those from SSM/I and buoy, IEEE T. Geosci. Remote Sens., 40, 1241-1246, 2012. 